\title{
Kosmischer Zweikampf zwischen Gut und Böse
}

Erhard Taverna

Der Autor und Kollege hat eine Art gnostische Evolutionstheorie des Bösen entwickelt: Lange bevor die ersten Engel existierten, begann das Wesen seine Existenz als feinstoffliche Ergänzung der Nahrungskette. Es nährte sich von negativen Gefühlen wie Angst, Schmerz, Schrecken oder Hass, bis es endlich mit dem Homo sapiens sapiens zu seiner Leibspeise fand: «It also learned a brand-new thrilling game it hadn't encountered while dealing with other life forms: the art oft negotiation.» Der Mensch in seiner Gier und Todesangst war immer für einen Tausch zu haben. So wurde der unersättliche Fresser süchtig nach diesem Seelenfutter, das aber nur mit der Einwilligung des Besitzers zu haben war. Damit kam die Versuchung als teuflischer Köder in die Welt: «Temptation was the key word, and with the mighty forces it had attained, the creature offered an unbeatable and unchallenged public service.» Von Dante Alighieri lernte das Ding mit seinen vielen Namen, dass der Mensch einen Ort für die ewige Bestrafung seiner Sünden brauchte: «Ever courteous to please his customers, Satan complied and thus created Hell.»

Das alles ist hübsch geflunkert und unterhaltsam erzählt. Der schon mehrfach ausgezeichnete Autor, Yves Etienne Patak, arbeitet als Arzt in Zürich und hat mit «The Healer» seinen ersten, englisch geschriebenen Roman publiziert. Eine spannend geschriebene Fantasygeschichte, die nach einem geheimnisvollen Anfang in der libyschen Wüste rasant an Tempo gewinnt und in der Nôtre Dame von Paris mit einem kosmischen Zweikampf zwischen Gut und Böse ein vorläufiges Ende findet. Der Autor montiert souverän die bekannten Requisiten des Misterythrillers zu einem dramatischen Showdown, der wie im Western unaufhaltsam seinem finalen Duell zustrebt. Die Handlung sei hier nicht verraten, nur etwas zum Personal. Es kommen vor eine Lichtgestalt namens Sharan und ihre böse Gegenspielerin die Hexe Michelle, drei Psychiater, wovon der eine, als erfolgreicher Exorzist, seinem hoffnungslos scholastischen Berufsverband und dessen Haldol Zombies die Gefolgschaft längst gekündigt hat, sowie viele Statisten eindeutiger und zweifelhafter Herkunft. Auch sei vorweggenommen, dass es sich um ein Männerbuch handelt. Die Stellvertreterinnen der patriarchalen Chefs sind traumhaft schön

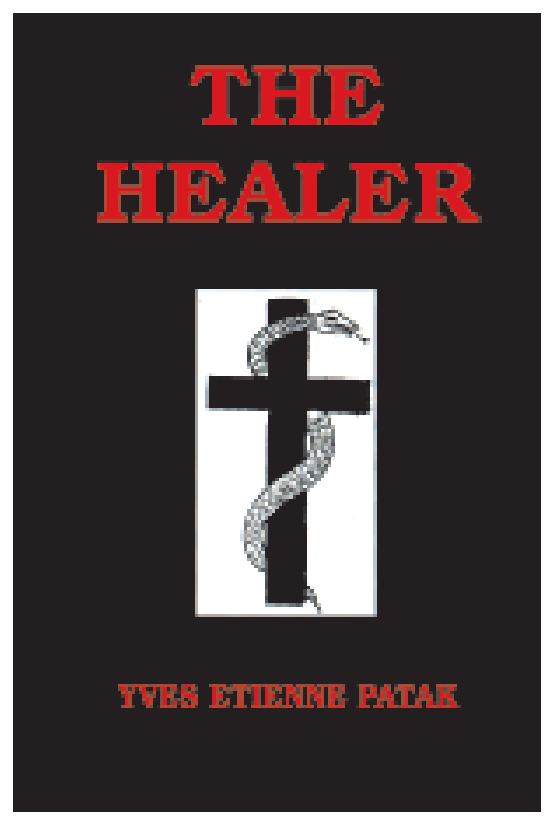

und sexy. Die eine vollzieht reihenweise ihre Instantexorzismen, die andere ist ein teuflisch geiles Monster in Kostümen, die Karl Lagerfeld gerne selber erfunden hätte. Die eine heilt mit dem spröden Charme einer Krankenschwester, die andere befriedigt sich mit schwarzen Kerzen oder bumst ihre männlichen Opfer, dass buchstäblich die Fetzen fliegen. Die tiefblauen Augen der Missionarin besänftigen unser besessenes Gemüt, die Tigergelben der Domina versprechen Ekstase und Höllenpein. Satanisten intonieren höllische Chöre an verruchten Orten, ein Kommissar fährt gegen eine Wand, Scheiterhaufen brennen, Astralkörper fliegen wie Batman ihrem Ziel entgegen, und ein Kollege wird mit einem Kruzifix gepfählt. Es stinkt nach Schwefel und Pech, was will man mehr.

Zwar jongliert Yves Etienne Patak mit allen Filmklischees aus Hollywoods Trickkiste von «Rosmary's Baby» über «The Alien» bis «The Exorzist», aber er macht es gekonnt, und er demonstriert einmal mehr, dass das Böse unsere Phantasie weit mehr befruchtet als das Gute.

Eine schaurig-schöne Freizeitlektüre, und erst noch auf Englisch!

The Healer, Yves Etienne Patak, Published by Vantage Press, Inc. 419 Park Ave. South, New York, 2005, ISBN: 0-533-15088-4, 324 Seiten. 